prognosis is good, accounts for few deaths in transplant recipients, ${ }^{2+}$ but $46 \%$ of patients with other tumours die of their malignancy or because of organ rejection after withdrawal of immunosuppression to prevent spread of the tumour. ${ }^{+}$Survival of transplant recipients with cancer is similar to that of those without tumours for the first eight years after transplantation but thereafter declines rapidly. ${ }^{15}$

Controlled multicentre studies (organised perhaps by the European Renal Association) are necessary to determine if tumours other than skin tumours occur more often in transplant recipients followed for at least five years. In the short term the risks seem small and do not detract from the benefits of successful transplantation, even in the elderly.

ALISON M MACLEOD Lecturer in Medicine GRAEME R D CATTO

University of Aberdeen, Professor of Medicine
Sheil AGR. Cancer in renal allograft recipients in Australia and New Zealand. Transplant Proc 1977;9:1133-6.

2 Hardie IR, Strong RW, Hartley LCJ, Woodruff PWH, Clunie GJA. Skin cancer in Caucasian renal allograft recipients living in a subtropical climate. Surgery 1980;87:177-83.

3 Sheil AGR, Mahony JF, Horvath JS, et al. Cancer following successful cadaveric donor renal transplantation. Transplant Proc 1981:13:733-5.

transplantation. Transplant Proc 1981,13:733-5.

5 Sheil AGR. Cancer after transplantation. World f Surg 1986;10:389-96.

(1973;ii:55-7.

6 Bieber CP, Hunt SA, Schwinn DA, et al. Complications in long-term survivors of cardiac transplantation. Transplant Proc 1981;13:207-11.

Kinlen L, Doll R, Peto J. The incidence of tumours in human transplant recipients. Transplant Proc 1983;15: 1039-42.

8 Wing AJ, Broyer M, Brunner FP, et al. Combined report on regular dialysis and transplantation in Europe, XII, 1982. In: Davison AM, ed. Proceedings of the European Dialysis and Transplan Association-European Renal Association. Vol 20. London: Pitman, 1983:5-75.

9 Kinlen LJ, Sheil AGR, Peto J, Doll R. Collaborative United Kingdom-Australasian study of cancer in patients treated with immunosuppressive drugs. Br Med f 1979;ii:1461-6.

10 Birkeland SA. Malignant tumours in renal transplant patients. Cancer 1983;51:1571-5.

11 Kelly GE, Mahoney JF, Sheil AGR, Meikle WD, Tiller DS, Horvath J. Risk factors for skin carcinogenesis in immunosuppressed kidney transplant recipients. Clinical Transplantation 1987;1:271-7.

12 Bunney MH, Benton EC, Barr B, et al. An external study of human papillomavirus infections in a group of Scottish renal allograft recipients. Nephrology, Dialysis and Transplantation (in press).

13 Calne RY, Rolles K, White DJG, et al. Cyclosporin A initially as the only immunosuppressant in 34 recipients of cadaveric organs: 32 kidneys, 2 pancreases, and 2 livers. Lancet 1979;ii: 1033-6. Cockburn I. Assessment of the risks of malignancy and lymphomas developing in patients using
. Cockburn I. Assessment of the risks of malignancy
Sandimmune. Transplant Proc 1987;19:1804-7.

15 Sheil AGR, Mahoney JF, Horvath JS, et al. Cancer survival after cadaveric donor renal transplantation. Transplant Proc 1979;11:1052-4.

\title{
Microdiscectomy for treating lumbar disc protrusion
}

\section{An important advance that merits wide adoption}

Four out of every five people experience an episode of disabling back pain during adulthood. Most episodes settle with conservative treatment, but many patients require an operation, the commonest indication for which is lumbar disc prolapse with nerve root compression. In Britain laminectomy is still the most widely used approach, though fenestration is becoming more popular. In either case a $10-12 \mathrm{~cm}$ incision is needed. The operation takes about an hour to perform, often requiring a transfusion of blood, and patients need a week to 10 days in hospital. It inflicts considerable muscle trauma with denervation' and reduced segmental movement because of scarring. ${ }^{2}$ There is a risk of infection, neurological damage, epidural haemorrhage, and arachnoiditis, and postoperative disability lasts from six weeks to six months. . $^{3-5}$

In an attempt to overcome this morbidity microdiscectomy has been developed over the past few years, principally for treating virgin disc herniations. ${ }^{6-12}$ It incorporates all the elements of the traditional approach but uses the operating microscope, which permits the operation to be performed through a $2 \mathrm{~cm}$ incision. No patient is considered for microdiscectomy without an adequate trial of conservative treatment. Radiculography or computed tomography is performed preoperatively to confirm the diagnosis and the level of the lesion. Microdiscectomy is contraindicated if there is any spinal stenosis. ${ }^{13}$

Because magnification and microinstruments are used minimal retraction of the nerve root is required. Extradural fat is preserved, minimising the chances of subsequent adhesions, and accurate bipolar coagulation is used resulting in a minimal loss of blood. It is often possible to pierce the annulus bluntly rather than incising it so that it closes like a valve, reducing the risk of recurrent disc prolapse. ${ }^{10}$ Unlike with conventional laminectomy, the surgeon sees the inside of the disc space, ${ }^{12}$ and video cameras may observe and record the operation. According to its proponents microdiscectomy takes about 30 minutes to perform, and blood transfusion is not necessary. Most patients leave hospital within two or three days. Indeed, some centres perform the operation on outpatients, and $90 \%$ of patients may resume their previous work without pain. ${ }^{1014}$

Technical errors include operating at the wrong level and failing to discover a sequestrated disc or recognise canal stenosis. Infection of the disc space and recurrent herniation may occur but are less common than with conventional techniques. ${ }^{11}$ For the right patients microdiscectomy is an important advance, and follow up studies have removed doubts about its long term results. ${ }^{115}$

Why then, with so much in its favour, has microdiscectomy not been more widely adopted? Some surgeons have not yet accepted microdiscectomy either because of a lack of experience or because of concern that the rate of complication may increase as many surgeons take up a new operation. Clearly adequate instruction has to be provided before it can be safely adopted on a wider scale and this will require a large training programme. The cost of providing equipment will also be substantial, but the cost to the community of not adopting these techniques would be even greater.

GLYN EVANS

Lecturer in Orthopaedics

R K JACKSON

Orthopaedic Department,

Southampton General Hospital,

Southampton SO9 4XY

1 Blom S, Lemperg R. Electromyographic analysis of the lumbar musculature in patients operated on for lumbar rhizopathy. $\mathcal{I}$ Neurosurg 1967;26:25-30.

2 Nystrom B. Experience of microsurgical compared with conventional technique in lumbar disc operations. Acta Neurol Scand 1987;76:129-41.

Wilson DH. Microsurgical and standard removal of the protruded lumbar disc. Neurosurgery 1981;8:422.

4 Armstrong JR. The causes of unsatisfactory results from the operative treatment of lumbar disc lesions. F Bone foint Surg [Br] 1951;33:31-5.

5 Macnab I. Negative disc exploration. I Bone foint Surg [Am] 1971;53:891-903.

6 Goald JG. Microlumbar discectomy: follow up of 147 patients. Spine 1978;3:183-5.

Williams RW. Microlumbar discectomy: a conservative approach to the virgin herniated lumbar disc. Spine 1978;3:175-82.

8 Wilson DH, Kenning J. Microsurgical lumbar discectomy: a preliminary report of 83 consecutive cases. Neurology 1979;4:137-40.

9 Goald HJ. Microsurgical removal of lumbar herniated nucleus pulposus. Surg Gynecol Obstet 1979;149:247-8.

10 Goald HJ. Microlumbar discectomy: follow-up of 477 patients. fournal of Microsurgery 1980;2 95-100.

11 Ebeling U, Reichenburg W, Reulen HJ. Results of microsurgical lumbar discectomy: review on 485 patients. Acta Neurochir (Wien) 1986;81:45-52.

12 Thomas AMC, Afshar F. The microsurgical treatment of lumbar disc protrusion: follow-up of 60 cases. J Bone Joint Surg [Br] 1987;69:696-8.

13 Sachdev VP. Microsurgical discectomy: a personal series of 300 patients with at least 1 year of follow-up. Microsurgery 1986;7:55-62.

14 Rogers LA. Outpatient management of ruptured lumbar discs. NC Med f 1987;48:117-20.

15 Williams RW. Microlumbar discectomy: a 12-year statistical review. Spine 1986;11:851-2. 